\title{
Unraveling foliar water uptake pathways: the contribution of stomata and the cuticle
}

\author{
Paula Guzmán-Delgado ${ }^{1}$, Emilio Laca ${ }^{2}$, and Maciej Zwieniecki ${ }^{1}$ \\ ${ }^{1}$ University of California Davis \\ ${ }^{2} \mathrm{UC}$ Davis
}

August 10, 2020

\begin{abstract}
Plants can absorb water through their leaf surfaces, a phenomenon commonly referred to as foliar water uptake (FWU). Despite the physiological importance of FWU, the pathways and mechanisms underlying the process are not well known. Using a novel experimental approach, we parsed out the contribution of the stomata and the cuticle to FWU in two species with Mediterranean (Prunus dulcis) and temperate (Pyrus communis) origin. The hydraulic parameters of FWU were derived by analyzing mass and water potential changes of leaves placed in a fog chamber. Leaves were previously treated with abscisic acid to force stomata to remain closed, with fusicoccin to remain open, and with water (control). Leaves with open stomata rehydrated two times faster than leaves with closed stomata and attained three to four times higher maximum fluxes and hydraulic conductance. Based on FWU rates, we propose that rehydration through stomata occurs primarily via diffusion of water vapor rather than in liquid form even when leaf surfaces are covered with a water film. We discuss the potential mechanisms of FWU and the significance of both stomatal and cuticular pathways for plant productivity and survival.
\end{abstract}

\section{Introduction}

Plants can absorb water through their non-woody aerial surfaces (Dawson and Goldsmith 2018; Rundel 1982; Stone 1957). This ability, commonly referred to as foliar water uptake (FWU) is shared across phylogeny, and may have profound implications for the water and carbon balance at both the plant and ecosystem level (Binks et al. 2019; Boanares et al. 2019; Hayes et al. 2020). Foliar water uptake can increase plant water status and primary productivity (Berry et al. 2014; Gouvra and Grammatikopoulos 2003; Eller et al. 2013; Fernández et al. 2014; Kerhoulas et al. 2020; Pina et al. 2016; Simonin et al. 2009), and enhance survival by potentially allowing the restoration of xylem transport capacity (Fuenzalida et al. 2019; Laur and Hacke 2014) or facilitating xylem/phloem transport during crucial phenological stages (e.g. fruit development or leaf senescence; Guzmán-Delgado et al. 2017, 2018). Nevertheless, there are many critical knowledge gaps that limit our understanding of FWU (Berry et al. 2019). For instance, the pathways and mechanisms underlying the process are poorly understood but are pivotal to deciphering the physiological functions and evolutionary significance of this trait.

Water may be absorbed through parallel pathways, including the cuticle/wax layer of ordinary epidermal cells, trichomes or guard cells, and stomatal or hydathode pores (Fernández and Eichert 2009; Martin and von Willert 2000; Schreel et al. 2020). Cuticular water uptake was found to be a very slow process involving fluxes in both liquid and vapor phases (Schreiber and Schönherr 2009). In contrast, studies evaluating stomatal FWU have provided divergent results. Water dissolved solutes or suspended particles applied to the leaf surface were either not observed to penetrate stomata (Eller et al. 2016; Schreel et al. 2020), found on the walls of stomatal pores (Arsic et al. 2020; Li et al. 2018), or on mesophyll cells lining the substomatal cavity ( $43 \mathrm{~nm}$ diameter suspended particles; Eichert et al. 2008). It is argued that stomatal anatomical and physico-chemical features prevent liquid water entry into the pore, unless it is forced by an external pressure 
or water surface tension and cuticular hydrophobicity are reduced by the action of surfactants or other substances such as deliquescent particles or bacteria present along the pores (Burkhardt et al. 2012; Eichert et al. 2008; Schönherr and Bukovac 1972). In particular, the hydrophobic cuticular ledges over guard cells present in many species with diverse phylogenetic origins and ecologies may serve this function (Cullen and Rudall 2016; Edwards et al. 1998; Hunt et al. 2017; Merced and Renzaglia 2013). Other epidermal structures like stomatal wax plugs, papillae or striations found in fossil and extant species of humid habitats may also contribute to keep stomatal pores free of liquid water thus allowing for gas exchange (Aparecido et al. 2017; Brodribb and Hill 1997; Jordan et al. 1998; Feild et al. 1998). Therefore, if and how stomata contribute to FWU remain open questions.

In general, 'closed' stomata (i.e. (near) null pore apertures) severely constrain the flow of both liquid and gaseous water. 'Open' stomata (i.e. greater pore apertures) enable significant vapor diffusion out of the leaf (transpiration; Lawson et al. 1998) and potentially also absorption when the vapor pressure inside the leaf is lower than the air outside (Vesala et al. 2017). Water droplet/film formation on the leaf surface may also allow the inflow of liquid water through open stomata (Eichert and Burkhardt 2001), which could dramatically increase FWU rates. However, since stomata seem to be designed to protect internal leaf tissues from liquid water entry, we hypothesize that their contribution to FWU is mostly realized by vapor diffusion, not a liquid path. To test our hypothesis, we applied a novel method that allows quantifying the temporal dynamics of leaf rehydration and hydraulic parameters associated with FWU using measurements of leaf mass and water potential changes in a fog chamber (Guzmán-Delgado et al. 2018). To determine the contribution of stomata to FWU we chemically modified stomatal aperture by the application of abscisic acid to keep stomata closed and of fusicoccin to force stomata open. We used leaves of two species that do not have trichomes or hydathodes to limit confounding water entry pathways. We found that 'open' stomata can accelerate the rehydration of moderately stressed leaves over rates observed for a cuticle 'only' path, although the increased rates fall short of suggesting the formation of a direct hydraulic path.

\section{Material and Methods}

Plant material

Fully developed, undamaged leaves of Prunus dulcis (Mill.) D.A. Webb and Pyrus communis L. were used for this study. Leaves of each species were selected from the central part of current-year sun-exposed shoots, of southeast facing branches in five mature trees growing at the University of California Davis campus $\left(38.542154^{\circ} \mathrm{N}, 121.796485^{\circ} \mathrm{W}\right.$, Davis, USA). Branches were randomly collected in the early morning, enclosed in dark plastic bags containing damp paper towels and transferred to the laboratory. Homogeneous looking leaves were chosen from branches for further experimental treatments and analyses.

Pressure-volume curves and target water potential

Pressure-volume curves were generated for each species to estimate the turgor loss point and select the initial leaf water potential $(\Psi)$ value for all FWU experiments. This target $\Psi$ value corresponded to $70 \%$ of the turgor loss point. We followed the bench drying technique (Hinckley et al. 1980) using six randomly selected leaves per species. Briefly, branches were cut underwater, placed in plastic bags to prevent transpiration, and allowed to fully rehydrate. Leaves were then detached from branches, weighed, and placed on a bench to desiccate at room conditions (relative humidity, $\mathrm{RH}, \sim 30 \%$ and temperature ${ }^{\sim} 22{ }^{\circ} \mathrm{C}$ ). Each leaf was reweighed, and its $\Psi$ was measured with a pressure chamber during the drying period. The procedure was halted when 10 to $15 \%$ of the initial leaf mass was lost. Leaves were oven-dried at $80^{\circ} \mathrm{C}$ for three days to calculate their relative water content $(\mathrm{RWC})$ as $\mathrm{RWC}=($ fresh weight-dry weight, DW)/(turgid weight-DW $)$. The turgor loss point was estimated from the pressure-volume curves.

Modification of stomatal aperture

Randomly selected leaves were treated to modify stomatal aperture with fusicoccin (FC; 'open' stomata), abscisic acid (ABA; 'closed' stomata), and water (control) (Jones and Mansfield 1970; Turner and Graniti 1969). We followed the procedure by Eichert et al. (1998) with some modifications. Leaves were collected 
from branches previously equilibrated at the target $\Psi$ (i.e. at approximately -1.7 and $-2.0 \mathrm{MPa}$ for $P$. dulcis and $P$. communis, respectively) and weighed. Leaf petioles were immersed in tubes filled with aqueous solutions of $10 \mu \mathrm{M}$ FC (Biomol, Hamburg, Germany), $10 \mu \mathrm{M}$ ABA (Sigma-Aldrich, Munich, Germany), or with deionized water for five to six hours. During the first two hours, leaves were kept at room conditions in a relatively dry atmosphere, to allow transpiration and enough uptake of the solutions. Leaves were then fully rehydrated in a dark and humid environment to restrict transpiration by placing them in individual chambers containing damp paper towels. At the end of the treatment period, $\Psi$ was confirmed to be higher than -0.05 MPa. Treatment effectiveness was determined by stomatal conductance measurements in dehydrating leaves and stomatal pore aperture in surface micrographs. Treated leaves were then used for surface rehydration kinetics experiments.

Stomatal conductance of dehydrating leaves

The effect of the chemical treatments on the stomatal conductance $\left(\mathrm{g}_{\mathrm{s}}\right)$ of leaves was assessed in relation to $\Psi$ as measured by balancing pressure. We used 24 randomly selected leaves of $P$. dulcis (10 FC, 7 ABA, 7 control) and 20 leaves of $P$. communis ( $7 \mathrm{FC}, 6 \mathrm{ABA}, 7$ control). For each leaf, $\mathrm{g}_{\mathrm{s}}$ was measured periodically during dehydration (from $\Psi$ close to zero to turgor loss point) using a portable photosynthesis system (LI6400, Li-Cor, Lincoln, NE, USA) in darkness, with an air flow of $1,000 \mu \mathrm{mol} \mathrm{s}{ }^{-1}$ and RH set at $70 \%$. The $\Psi$ was recorded after each $\mathrm{g}_{\mathrm{s}}$ measurement. Initial trials showed that at room conditions, leaves - especially FC treated leaves - dehydrated rather fast, limiting the number of measurements that could be performed when still turgid. Thus, to reduce the speed of dehydration, leaves were kept in dark, small containers filled with wet paper towels between measurements. The relationship between $\mathrm{g}_{\mathrm{s}}$ and $\Psi$ was assessed by fitting data to a linear mixed-effect model with treatment as fixed factor and leaf as random factor. Data were compared at the average $\Psi$ value (least-square mean) predicted for all the treatments and both species using analysis of variance (ANOVA) and Tukey tests. The model was also used to estimate $\mathrm{g}_{\mathrm{s}}$ at $\Psi$ values when maximum flux $\left(\mathrm{Q}_{\max }\right)$ and maximum hydraulic conductance $\left(\mathrm{K}_{\max }\right)$ were reached and evaluate potential correlations. Statistical analyses were performed with R (v.3.5.1, the R Foundation for Statistical Computing, Vienna, Austria).

Effect of FC and $\mathrm{ABA}$ on leaf rehydration via the adaxial surface

To evaluate the potential effects of FC and ABA treatments on water uptake and leaf rehydration not associated with changes in stomatal aperture, a preliminary experiment aiming to analyze FWU via only the adaxial, stomata-free surface was conducted with $P$. dulcisleaves. The abaxial surfaces and margins of fully rehydrated leaves supplied either with FC, ABA or water (six leaves per treatment) were covered with paraffin wax, and their cut-end petioles sealed. Leaf mass was recorded before and after wax application, as well as before treatment application. Leaves were allowed to dehydrate until reaching the mass associated with the target $\Psi$ and placed in a 'fog chamber' (see below). After 100-120 min of fog exposure, leaves were taken out of the chamber and weighed after their surface was dried with pulses of dry air. A second set of leaves of each treatment (three leaves per treatment) was fully covered with wax, i.e. both their adaxial and abaxial surface, and placed in the chamber. After 100-120 min, the mass of the leaves from this second set remained the same which confirms that wax application was effective in sealing the surface. After the rehydration experiment, leaves were scanned and their area was calculated with ImageJ (v.1.45s National Institutes of Health, Bethesda, MD, USA). The amount of water absorbed via the adaxial leaf surface was calculated as the increment in mass following fog application per projected leaf surface area; the treatment effect was assessed by ANOVA in R.

Surface rehydration kinetics

The kinetics of leaf rehydration via the surface was analyzed as described by Guzmán-Delgado et al. (2018). Leaves treated with FC and ABA and control leaves were allowed to slowly dehydrate to the mass corresponding to the target $\Psi$ and recorded prior to treatment application. We randomly selected 25 leaves per treatment. However, leaves that reached mass values lower than those previously recorded were discarded. Thus, we performed measurements in 21, 22 and $25 \mathrm{FC}, \mathrm{ABA}$ and control P. dulcis leaves, respectively, and 
in 18, 22 and $23 \mathrm{FC}, \mathrm{ABA}$ and control $P$. communis leaves, respectively. Leaves with vacuum grease sealed petioles were individually suspended in a dark chamber at ${ }^{2} 2{ }^{\circ} \mathrm{C}$ connected to an ultrasonic humidifier producing submicron fog droplets. Leaves were taken out of the rehydration chamber after approximately $10,20,30$, etc. min until $\Psi$ was approaching to zero, and patted dry with paper towels. The mass and $\Psi$ of each leaf were then measured. The area and DW of the leaves were measured after scanning and oven-drying, respectively. The cumulative amount of absorbed water and $\Psi$ of each leaf were plotted against time and fit with modified exponential functions (Table 1 Supporting Information). The apparent hydraulic resistance to flow $(\mathrm{R})$ between the water source (wet leaf surface, $\Psi_{\mathrm{H} 2 \mathrm{O} \text { source }}=0$ ) and rehydrating tissues was calculated from Ohm's equation as $\mathrm{R}=\Psi / \mathrm{Q}$, where $\mathrm{Q}$ is the instantaneous flux of water into the leaf calculated as the first derivative of the mass gain function. Confidence intervals and tests of hypothesis were performed by residual bootstrapping with $\mathrm{R}$.

Microscopy (ESEM)

Leaves treated with FC and $\mathrm{ABA}$ and control leaves were analyzed with an environmental scanning electron microscope (ESEM, FEI Quanta 200, North America NanoPort, Portland, OR, USA; acceleration potential $10 \mathrm{kV}$; working distance $10 \mathrm{~mm}$; Gaseous Secondary Electron Detector 6.2 Torr). This technique enables the observation of samples in their native state, i.e. without involving any previous sample preparation, as well as the study of condensation processes at high resolution (Burkhardt and Hunsche 2013; Cheng et al. 2005). For each species, three randomly selected leaves per treatment were used. Sections of approximately $20 \mathrm{~mm}^{2}$ were obtained from the mid-region of the leaves, avoiding venation as much as possible, and placed on the microscope stage. A Peltier chip attached to the stage allowed temperature and thus RH control. Temperature was kept between 7 and $5{ }^{\circ} \mathrm{C}$ to achieve $\mathrm{RH}$ values between 50 and $100 \%$ during examination. Stomatal pore aperture (width) and density were measured in the micrographs using ImageJ. Pore aperture was measured in stomata that allowed clear pore limit identification, with 54 (FC), 65 (ABA) and 45 (control) stomata being analyzed in $P$. dulcis, and 44 (FC), 40 (ABA) and 36 (control) in P. communis (with a minimum of 15 ( $P$. dulcis ) and 12 (P. communis ) stomata per leaf). Stomatal density was determined in six leaves per species. Pore width was analyzed using a linear mixed-effect model with treatment as fixed factor and leaf and micrograph as random factors (micrograph nested within the leaf), and Tukey tests in R.

\section{Microscopy (TEM)}

Freshly collected leaves were analyzed by transmission electron microscopy (TEM). Samples were prepared as described by Guzmán et al. (2014a) with slight modifications. Leaf segments $\left(4-\mathrm{mm}^{2}\right)$ were cut from the mid-region of the blade. Segments were then fixed in ice-cold $2.5 \%$ glutaraldehyde and $2 \%$ paraformaldehyde in $0.1 \mathrm{M}$ phosphate buffer, $\mathrm{pH} 7.3$, and kept at $4{ }^{\circ} \mathrm{C}$ prior to further preparation steps. Samples were then rinsed with cold phosphate buffer $(\mathrm{x} 4)$ and post-fixed in a $2 \%$ osmium tetroxide and $3 \%$ potassium ferrocyanide aqueous solution for $1.5 \mathrm{~h}$. Tissues were washed with distilled water (x3), dehydrated in a graded series of 30, 50, 70, 80, 90, 95 and $100 \%$ acetone (x2, 15 min per concentration) and embedded in acetone-Spurr's resin (Spurr's low viscosity embedding media, Electron Microscopy Sciences, Hatfield, PA, USA) solutions ( $3: 1,2 \mathrm{~h} ; 1: 1,2 \mathrm{~h} ; 1: 3 ; 3 \mathrm{~h}(\mathrm{v}: \mathrm{v}))$ and in pure resin (overnight) at room temperature $\left(20{ }^{\circ} \mathrm{C}\right)$. Tissues were finally embedded in blocks which were incubated for 3 days at $70{ }^{\circ} \mathrm{C}$. Ultrathin sections were cut, and post-stained with uranyl acetate and lead citrate. Sections were subsequently observed with a FEI Talos 120C TEM (Tokyo, Japan) operated at $80 \mathrm{kV}$ and equipped with a FEI Ceta CMOS camera. Stomatal pore depth and cuticle thickness were measured in the micrographs using ImageJ. Pore depth was measured in six open stomata per species. Cuticle thickness (excluding the epicuticular wax layer) was measured in ordinary epidermal cells, subsidiary cells, and guard cells, both in the external and internal (substomatal) periclinal regions, as well as in guard cell anticlinal regions (along the pore). Measurements were performed in a minimum of six cells of each type with about 10 repetitions, and results were compared using ANOVA and Tukey tests with R.

\section{Results}


Effect of FC and ABA treatments - stomatal conductance of dehydrating leaves

For both species, treatments significantly affected $\mathrm{g}_{\mathrm{s}}(P<0.0001$, Table 2 Supporting Information $)$. The $\mathrm{g}_{\mathrm{s}}$ of $P$. dulcis and P. communis was higher for FC than for ABA and control leaves (Table 1, Figure 1). Very small negative values of $\mathrm{g}_{\mathrm{s}}$ recorded for $P$. dulcis $\mathrm{ABA}$ and control leaves were likely associated with transpiration rates below the detection limit of the photosynthesis system and not significantly different from 0 , suggesting that stomata were mainly shut. The $\mathrm{g}_{\mathrm{s}}$ for the different treatments is consistent with values reported for plants growing in field conditions (Marsal and Girona 1997; Spinelli et al. 2016). For both species, values of $\mathrm{g}_{\mathrm{s}}$ indicate that treatments were effective in modifying stomatal aperture across the $\Psi$ range where FWU was analyzed (Figure 1). The observed variation of $\mathrm{g}_{\mathrm{s}}$ with $\Psi$ suggests that, despite the treatments, stomatal responses were still affected by $\Psi$. However, FC forced stomata to remain open even under significant stress. ABA treatment was also successful in both species reducing $g_{s}$ to near zero. The control treatment seemed to almost fully close stomata in $P$. dulcis but not in $P$. communis, providing the opportunity to test the contribution of partially shut stomata to FWU.

Effect of FC and ABA treatments - ESEM microscopy assessment

ESEM analyses provided direct evidence that treatments modified stomatal aperture (Figure 2). Since ESEM images do not show pore walls as the electron beam is shielded by cuticular ledges, we used the distance (width) between the ledges as a proxy for stomatal pore aperture (Figure 2a, c, d). Treatments significantly influenced stomatal aperture in both $P$. dulcis and $P$. communis $(P<0.0001$, Table 3 Supporting Information). The width (mean \pm se in $\mu \mathrm{m}$ ) between ledges was greater in FC leaves $(2.53 \pm 0.11)$ than in ABA $(0.57 \pm 0.10)$ and control leaves $(0.50 \pm 0.11)$ of $P$. dulcis $(P<0.0001 ; P=0.819$ for ABA vs control leaves). In $P$. communis, FC treated leaves also had the largest pore width $(2.07 \pm 0.12)$, followed by control $(1.38 \pm 0.13)$ and then ABA $(0.83 \pm 0.12)$ treated leaves $(P<0.005)$. Differences in stomatal pore apertures agree with differences in the fluxes recorded, both $g_{\max }$ and $\mathrm{Q}_{\max }$ (Figure 1a, b Supporting Information). The density of stomata was $211.5 \pm 1.6$ and $179.8 \pm 2.0$ stomata $\mathrm{mm}^{-2}$ in $P$. dulcis and $P$. communis , respectively.

Simulated fog conditions by an increase of RH up to $100 \%$ in the microscope chamber revealed different stages of water condensation that were affected by time and leaf surface location. Roughly, water first condensed as relatively small droplets onto epidermal furrows among epidermal cell wall folds. These droplets increased in size by further condensation until coalescing, eventually forming films that covered all the furrows. Larger droplets appeared later on top of the folds which were then fully covered by a water film. Up to that point stomata were not covered with water. Further water accumulation resulted in the formation of a water film covering the entire leaf surface.

\section{Surface rehydration kinetics}

In both species, leaf exposure to artificial fog led to full leaf rehydration via FWU across all treatments (Figure 3). Leaf rehydration kinetics, in terms of gain in mass and $\Psi$ increment over time, was fit with exponential curves (Table 1 Supporting Information) to calculate specific components of the absorption process. Based on fit estimates, $P$. dulcis leaves absorbed between 9.9 to $13.2 \mathrm{~g} \mathrm{~m}^{-2}$, and $P$. communis leaves between 8.5 to $13.5 \mathrm{~g} \mathrm{~m}^{-2}$ (or $\sim 0.1 \mathrm{~g} \mathrm{~g}^{-1} \mathrm{DW}$ in all cases). The $\Psi$ after prolonged rehydration stabilized within -0.4 to $-0.7 \mathrm{MPa}$ in P. dulcis and -0.3 to $-0.7 \mathrm{MPa}$ in P. communis .

In all treatments, abaxially sealed $P$. dulcis leaves absorbed the about same amount of water through their adaxial stomata-free surface ( $P=0.873$, Table 4 Supporting Information). After approximately 2 hours of fog exposure, FC, ABA and control leaves had respectively absorbed $2.1 \pm 0.3,2.0 \pm 0.3$ and $2.2 \pm 0.3$ $\mathrm{g} \mathrm{m}^{-2}$. This suggests that, at least for this species, treatments did not have a significant influence on the hydraulic properties of the cuticle and on leaf surface rehydration, so that differences in the parameters measured in non-sealed leaves can be distinctly attributed to stomatal apertures. This quantity of water was approximately half of the water absorbed by non-sealed leaves with stomata mainly closed (control and ABA treated leaves) after $\sim 2$ hours of fog exposure, suggesting that cuticle permeability of adaxial and abaxial surfaces is similar in P. dulcis . 
In both species, half-times ( $\mathrm{t}_{50}$; time at which $50 \%$ of mass and $\Psi$ increments are reached) were significantly shorter for FC than for ABA treated leaves (Table 1, Figure 3a-d), indicating faster rehydration and $\Psi$ recovery via FWU in leaves with open stomata. Similarly, maximum water flux $\left(\mathrm{Q}_{\max }\right)$ was approximately 3 times greater for FC than for ABA treated leaves of both species (Table 1). Maximum hydraulic conductance ( $\mathrm{K}_{\max }$; inverse of minimum resistance, $\mathrm{R}_{\min }$ ) was 4 and 3 times greater in $\mathrm{FC}$ than ABA treated leaves of $P$. dulcis and $P$. communis, respectively (Table 1, Figure $3 \mathrm{e}, \mathrm{f}$ ). Both $\mathrm{Q}_{\max }$ and $\mathrm{R}_{\min }$ were reached between 2.3 and 2.7 times faster in FC than $\mathrm{ABA}$ treated leaves (Table 1). At the time of $\mathrm{R}_{\min }, \Psi$ in $P$. dulcis was about $-0.7 \mathrm{MPa}$ (FC) and -1.1 MPa (both ABA and control), and about $-1.1 \mathrm{MPa}$ in P. communis (all treatments), which represents a respective $\Psi$ decrease of about $63 \%, 35 \%$ and $42 \%$ relative to initial $\Psi$ values. Despite the remarkably higher $\mathrm{g}_{\mathrm{s}}$ of $P$. communis $\mathrm{ABA}$ and control leaves compared to that of $P$. dulcis, the FWU rate $\left(Q_{\max }\right)$ was similar in both species. In contrast, similar $g_{s}$ values were attained by FC leaves of both species, but the FWU rate in $P$. communis was only half of that recorded in $P$. dulcis (Table 1 ).

Ultrastructure of the stomata and the cuticle - TEM microscopy

Cross-section analyses revealed the fine structure of the stomata and the cuticle of the two species (Figure 4). In both species, stomata have prominent outer cuticular ledges, as well as inner cuticular ledges which seem to be more developed in $P$. communis (Figure $4 \mathrm{a}, \mathrm{b}$ ). With varying but mostly reduced thickness, the abaxial cuticle extends from the ordinary epidermal cells along the stomatal pore, lining the substomatal chamber. This substomatal cuticle is even present in some parenchymatic cells, especially in $P$. communis (Figure 4c, d). The adaxial cuticle of both species shows an amorphous outer region that appears as a more electron-lucent band than the cuticle underneath, and an inner reticulate region at the interface with the more electron-dense, pectin-rich cell wall region (Figure 4e, f), as previously described for P. communis when prepared following the conventional Spurr's resin embedding protocol (Guzmán et al. 2014a). The epicuticular wax layer persisting after sample preparation procedures is more conspicuous in $P$. communis than P. dulcis . For both species, the appearance of the abaxial cuticle is similar, but structural details could not be observed when the cuticle was very thin. Cuticle thickness varied among cells and cell regions in both $\operatorname{species}(P<0.0001$, Table 5 Supporting Information). The outer periclinal cuticle of ordinary epidermal cells was of similar thickness in both leaf sides in P. dulcis $\left({ }^{\sim} 0.88 \mu \mathrm{m}\right)$, and thinner in the adaxial than in the abaxial side in $P$. communis $(\sim 1.65$ vs $\sim 1.98 \mu \mathrm{m})$. The outer periclinal cuticle of guard cells was thinner than that of ordinary and subsidiary cells, with average values of $0.33 \mu \mathrm{m}$ in $P$. dulcis and $0.55 \mu \mathrm{m}$ in $P$. communis. The cuticle was thinnest from the central pore region inwards in P. dulcis $(\sim 0.05 \mu \mathrm{m})$, and at the anticlinal region of guard cells (i.e. along the stomatal pore) and inner periclinal region of ordinary epidermal cells in P. communis $(\sim 0.22 \mu \mathrm{m})$, i.e. there is an increase in thickness of the internal cuticle at the proximity of the stomatal pore in $P$. communis . Stomatal pore depth as measured in TEM micrographs (Figure $4 \mathrm{a}, \mathrm{b}$ ) was $6.73 \pm 0.02 \mu \mathrm{m}$ in $P$. dulcis and $10.02 \pm 0.02 \mu \mathrm{m}$ in $P$. communis .

\section{Discussion}

\section{Mechanisms of FWU}

The presented results unequivocally show that open stomata contribute to FWU and highlight the role of the cuticle in the process. In both $P$. dulcis and $P$. communis, ('fully') open stomata by FC treatment resulted in increased water absorption rates across the entire $\Psi$ range evaluated relative to a 'cuticular only' path (stomata 'closed') and to partially open stomata (Figure 3). Indeed, open stomata reduced the time for full $\Psi$ recovery via FWU by up to half and enabled up to 3-4 times higher fluxes and hydraulic conductance (i.e. $\mathrm{Q}_{\max }$ and $\mathrm{K}_{\max }$, Table 1). Interestingly, the hydraulic resistance $\left(\mathrm{R}_{\min }\right)$ of $P$. dulcis leaves with open stomata, was the same as that estimated for the mesophyll or high-resistance leaf compartment when water was supplied via the petiole (260 MPa m² $\mathrm{s} \mathrm{g}^{-1}$; Guzmán-Delgado et al. 2018; Zwieniecki et al. 2007). It must be, however, mentioned that in that study leaves were younger (collected in May) than in the present study (collected in September), leading to differences in P. dulcis FWU parameters (e.g. $\mathrm{R}_{\text {min }}$ of intact leaves was $\sim 660$ vs $\sim 1,000 \mathrm{MPa} \mathrm{m}^{2} \mathrm{~s} \mathrm{~g}^{-1}$ in May and September, respectively). Such a discrepancy might indicate that FWU is influenced by temporal changes in leaf surface properties, as reported by Cavallaro et al. (2020). Even if open stomata facilitate FWU, the rates are still orders of magnitude lower than the hydraulic suction 
via the petiole, which suggests that a simple flow of liquid water into the leaf via stomata does not occur.

To further asses the principles of water movement into a leaf from its wet surface across open stomata, we can first calculate the flux if liquid bridges covering the pore volume were formed. For simplicity we assume that open stomata are cylinders of radius equal to half of the maximum pore width recorded here $(\mathrm{r}=1.27$ $\mu \mathrm{m}$ for $P$. dulcis and $\mathrm{r}=1.04 \mu \mathrm{m}$ for $P$. communis $)$ and length equal to the average pore depth $(1=6.73$ $\mu \mathrm{m}$ for $P$. dulcis and $\mathrm{l}=10.00 \mu \mathrm{m}$ for $P$. communis $)$. Considering a pressure difference equal to the $\Psi$ at $\mathrm{Q}_{\max }(\Delta \Psi=1.11 \mathrm{MPa}$ for $P$. dulcis and $\Delta \Psi=1.27 \mathrm{MPa}$ for $P$. communis $)$ and using measured stomatal densities $\left(\rho=211.5\right.$ stomata $\mathrm{mm}^{-2}$ for $P$. dulcis and $\rho=179.8$ stomata $\mathrm{mm}^{-2}$ for $P$. communis $)$, we can estimate the flux of liquid water $\left(\mathrm{Q}_{1}\right)$ through the porous epidermis using the Hagen-Poiseuille equation $\left(\mathrm{Q}_{1}\right.$ $=\left[\pi \mathrm{r}^{4} \Delta \Psi / 8 \eta_{\mathrm{w}} \mathrm{l}\right] \rho^{\cdot}$ where $\eta_{\mathrm{w}}$ is water dynamic viscosity). The estimated liquid flux would be $4.0 \mathrm{x} 10^{4}$ and $1.2 \times 10^{4} \mathrm{~g} \mathrm{~m}^{-2} \mathrm{~s}^{-1}$ for $P$. dulcis and $P$. communis, respectively. Even with the highly conservative assumption of path resistance equal to half of the leaf thickness $1[?] 150 \mu \mathrm{m}$, the respective flow rate would be $1.8 \times 10^{3}$ and $7.7 \times 10^{2} \mathrm{~g} \mathrm{~m}^{-2} \mathrm{~s}^{-1}$, yet the observed flux was in the range of $\sim 2.5 \times 10^{-3} \mathrm{~g} \mathrm{~m}^{-2} \mathrm{~s}^{-1}$, i.e. about six orders of magnitude lower, thus precluding the possibility of flood type water penetration via open stomata. Hence, we have to consider another, more plausible scenario, where hydrophobic ledges over guard cells (Figure $4 \mathrm{a}, \mathrm{b})$ prevent the formation of liquid bridges through stomatal pores, but still allow for the formation of a water film over the pore, as intuited from ESEM analyses. In such a scenario, we can raise a question as to whether vapor diffusion across open stomata can account for the observed increase in flux over that of cuticular uptake only. Assuming the same parametrization (stomatal density, p, pore radius, r, and pore length, l) as for liquid flow, and using only the epidermis thickness as the barrier for vapor flux we can estimate the vapor flux $\left(\mathrm{Q}_{\mathrm{v}}\right)$ through stomata using the general diffusion equation based on Fick's laws $\left(\mathrm{Q}_{\mathrm{v}}\right.$ $=[\mathrm{D} \Delta \mathrm{C} / \mathrm{l}] \pi \mathrm{r}^{2} \rho$, where $\mathrm{D}$ is the diffusion coefficient of water vapor in air, and $\Delta \mathrm{C}$ is the concentration gradient between saturated air at the droplet surface and air at $\sim 99 \%$ humidity in the leaf air space). By adding the contribution of the cuticle ( $Q_{\max }$ for ABA leaves) to the calculated vapor flux through stomata, we obtain fluxes of $2.02 \times 10^{-3}$ and $1.01 \times 10^{-3} \mathrm{~g} \mathrm{~m}^{-2} \mathrm{~s}^{-1}$ for $P$. dulcis and $P$. communis, respectively, which are within the same order of magnitude as those recorded $\left(3.35 \times 10^{-3}\right.$ and $\left.1.97 \times 10^{-3} \mathrm{~g} \mathrm{~m}^{-2} \mathrm{~s}^{-1}\right)$. If the path length is increased to $150 \mu \mathrm{m}$, the respective vapor fluxes are still $1.15 \times 10^{-3}$ and $6.83 \times 10^{-4} \mathrm{~g} \mathrm{~m}^{-2} \mathrm{~s}^{-1}(65 \%$ difference). This simple, conservative analysis provides strong support for the notion that, in the presented case, the main mechanism of water entry though stomata is vapor diffusion. There is, however, space for a marginal amount of water entering the leaf as submicron suspended water droplets (some fog droplets; Eichert et al. 2008), and as thin water films created along the pore walls of few stomata (Burkhardt et al. 2012; Eichert and Burkhardt 2001; Eichert et al. 2008). Additionally, even if epidermal surfaces are not wet, dehydrated organs can rehydrate from near saturated air (close to $100 \% \mathrm{RH}$, and higher than air $\mathrm{RH}$ of the stressed tissue; $\Delta \mathrm{C}>0$ ) at the surface, as previously predicted (Binks et al. 2020; Vesala et al. 2017) and experimentally found (Guzmán-Delgado et al. 2017; Laur and Hacke 2014).

Using chemical treatments on plants may result in equivocal responses of the physical processes under study if affected by the biological activity influenced by the treatment. Both FC and ABA were shown to modify membrane permeability, sometimes affecting leaf hydraulic properties (Blatt and Clint 1989; Coupel-Ledru et al. 2017). While this effect could not be avoided, our trial evaluating FWU via the adaxial surface of FC, ABA and control leaves of $P$. dulcis suggests that cuticular uptake was not affected by the treatments, so that the effect of open stomata leading to increased FWU is related to a new water pathway and not changes in membrane permeability. The lack of a significant effect on FWU by chemically induced variations in membrane hydraulic properties also suggests that FWU is dominated by the resistance related to the physico-chemical properties of the cuticle and by vapor diffusion, but not membrane facilitated liquid fluxes. Thus, the epidermal surface acts as a high-resistance pathway controlling the kinetics of leaf rehydration via FWU (Fuenzalida et al. 2019; Guzmán-Delgado et al. 2018). Most importantly, the pattern of leaf rehydration is independent from the absorption pathway, whether it is the cuticle or the cuticle with open stomata, suggesting a similar internal path for water redistribution.

Foliar water uptake $\left(\mathrm{K}_{\max }\right)$ increased significantly with increasing $\mathrm{g}_{\mathrm{s}}\left(\mathrm{R}^{2}=0.9999, p<0.001\right.$, Figure $1 \mathrm{c}$ Supporting Information), but the slope was significantly greater in $P$. communis than in $P$. dulcis . The absence 
of a common relationship across species was also found by Limm et al. (2009), and may indicate that species-specific stomatal features, leaf rheology and tortuosity of the mesophyll path when stomata are open can exert further influence on the absorption process. Indeed, while both species show traits that could be associated with greater protection against excess water entry (and dehydration), such as outer and inner cuticular ledges and substomatal cuticles, P. communis - the species with lower FWU capacity (lower $\mathrm{K}_{\max }$ ) - has more prominent inner ledges and a cuticle that extends farther into the substomatal cavity, even lining parenchymatic cells (Figure 4). Furthermore, changes in the properties of the chemically heterogeneous cuticle and other cell wall regions underneath can affect the species' capacity for FWU through stomata, and when the cuticle is the dominant path (Boanares et al. 2018; Guzmán et al. 2014a,b; Guzmán-Delgado et al. 2018). These changes may be driven by the stages of cuticle hydration, starting with a partial wetting of the cuticle from the outer towards the inner side, followed by epidermal cell rehydration and then rewetting of the cuticle from its inner side (towards the leaf surface), shortening the diffusion pathways and creating liquid bridges (Guzmán-Delgado et al. 2018).

Physiological implications of FWU pathways

Even with open stomata, FWU is insufficient to provide any meaningful absorption of water to sustain prolonged transpiration. To put it in the quantitative context, the maximum FWU rate with open stomata measured in this study was $\sim 12 \mathrm{~g} \mathrm{~m}^{-2} \mathrm{~h}^{-1}$ which is $\sim 80$ times lower than typical transpiration rates reported for the studied species $\left({ }^{\sim} 1,000 \mathrm{~g} \mathrm{~m}^{-2} \mathrm{~h}^{-1}\right.$ or $15 \mathrm{mmol} \mathrm{m}^{-2} \mathrm{~s}^{-1}$; Romero et al. 2004). Thus, 10 hours of fog water absorption at maximum FWU rates would support 7 minutes of transpiration. However, water stress results in a decreased $\mathrm{g}_{\mathrm{s}}$ and significantly reduced transpiration. In such conditions, FWU may be decisive for survival by temporarily recovering $\Psi$ and leaf turgidity. For example, a tree crown with $10 \mathrm{~m}^{2}$ of foliage could absorb $\sim 400 \mathrm{~g}$ of water over 10 hours via the cuticle only ( $1,200 \mathrm{~g}$ if stomata are open). While this amount seems small in comparison to transpirational requirements, if placed in the perspective of total leaf water content (2,000 g assuming $300 \mu \mathrm{m}$ leaf thickness and $66 \%$ cellular content), $400 \mathrm{~g}$ is not only more than enough to recover turgor $(\sim 200 \mathrm{~g})$ and $\Psi$, but can also provide water to locally refill embolized conduits (Earles et al. 2016), allow for maintenance of phloem activity, and partially rehydrate basal organs (Cassana et al. 2016).

The contribution of stomata to FWU highlights the importance of favorable timing when both plant and atmospheric conditions are conducive to absorption (e.g. conditions that promote stomatal opening during a precipitation event, and at night). This agrees with Berry et al. (2014) who found that the timing of fog exposure had a greater impact on FWU than the duration of surface wetness, probably associated with the role of open stomata in FWU. Under such favorable conditions, a number of species keep stomata open (Merilo et al. 2018; Resco de Dios et al. 2019; Schulze et al. 1972), thus maximizing FWU. In this regard, increasing FWU capacity can be a potential function for nocturnal stomatal conductance which is in line with its positive effect on plant growth (Resco de Dios et al. 2019). However, the contribution of the cuticle to FWU should not be underestimated. In addition to constituting a ubiquitous FWU pathway, its cuticular permeability can be essential to enable stomatal opening in response to $\Psi$ increase, potentially extending the photosynthetic period and enhancing $\mathrm{CO}_{2}$ uptake rates. This could lead to higher plant water use efficiency (Vesala et al. 2017). Differential uptake of water by guard cells and ordinary epidermal cells may restore turgidity in guard cells faster forcing stomata to open as they push against the still dehydrated epidermal cells (Buckley 2019). The hypothesized higher permeability of the exposed guard cell cuticle (Maier-Maercker 1983; Schlegel et al. 2005), or the presence of amorphous cellulose regions in the cell wall underneath (Shtein et al. 2017) might favor water fluxes into guard cells.

\section{Conclusions}

We have demonstrated that stomata may constitute a major pathway for FWU when open. The measured water fluxes suggest that the main mechanism underlying the transport of water across stomata is vapor diffusion through the stomatal pore, with in-leaf distribution being a combination of diffusion and liquid paths (same as across the cuticle). Further, we propose that the interplay between cuticular conductance and the capacity of the stomata to remain open can be a specific trait that allows for opening stomata in response 
to surface hydration. The total amount of water absorbed by FWU cannot sustain transpiration, but it can provide a means of survival allowing for the recovery of plant physiological functions after severe stress. Future research on leaf surface dynamics, e.g. stomatal responses to water condensation and temperature or cuticular changes as affected by temperature or degree of hydration can contribute to better understand FWU mechanisms and functional significance.

\section{Acknowledgements}

The authors are grateful to Ken Foster (Kennan Corporation, Davis) and Judy Callis (UC Davis) for providing FC and ABA. P.G.-D. was supported by a Katherine Esau Postdoctoral Fellowship (UC Davis).

\section{Author contribution}

PG-D and MZ conceived the study and designed the methods. PG-D performed the experiments. EL and PG-D carried out the statistical analyses. All the authors contributed to writing the manuscript.

\section{Conflict of Interest}

The authors do not have any conflict of interest to declare.

\section{References}

Aparecido L.M., Miller G.R., Cahill A.T. \& Moore G.W. (2017). Leaf surface traits and water storage retention affect photosynthetic responses to leaf surface wetness among wet tropical forest and semiarid savanna plants. Tree Physiology, 37, 1285-1300.

Arsic M., Le Tougaard S., Persson D.P., Martens H.J., Doolette C., Lombi E., Schjoerring J.K. \& Husted S. (2020). Bio-imaging techniques reveal foliar phosphate uptake pathways and leaf phosphorus status. Plant Physiology . doi: https://doi.org/10.1104/pp.20.00484

Berry Z.C., White J.C. \& Smith W.K. (2014). Foliar uptake, carbon fluxes and water status are affected by the timing of daily fog in saplings from a threatened cloud forest. Tree Physiology, 34, 459-470.

Berry Z.C., Emery N.C., Gotsch S.G. \& Goldsmith G.R. (2019). Foliar water uptake: Processes, pathways, and integration into plant water budgets. Plant, Cell and Environment , 42, 410-423.

Blatt M.R. \& Clint G.M. (1989). Mechanisms of fusicoccin action: kinetic modification and inactivation of $\mathrm{K}^{+}$channels in guard cells. Planta, 178, 509-523.

Binks O., Mencuccini M., Rowland L., da Costa A.C., de Carvalho C.J., Bittencourt P., Eller C., Sales Teodoro G., Carvalho E.J., Soza A. \& Ferreira L. (2019). Foliar water uptake in Amazonian trees: evidence and consequences. Global Change Biology, 2019, 1-13.

Binks O., Coughlin I., Mencuccini M. \& Meir P. (2020). Equivalence of foliar water uptake and stomatal conductance?. Plant, Cell and Environment, 43, 524-528.

Buckley T.N. (2019). How do stomata respond to water status? New Phytologist, 224, 21-36.

Boanares D., Ferreira B.G., Kozovits A.R., Sousa H.C., Isaias R.M.S. \& França M.G.C. (2018). Pectin and cellulose cell wall composition enables different strategies to leaf water uptake in plants from tropical fog mountain. Plant Physiology and Biochemistry, 122, 57-64.

Boanares D., Kozovits A.R., Lemos-Filho J.P., Isaias R.M., Solar R.R., Duarte A.A., Vilas-Boas T. \& Franca M.G. (2019). Foliar water-uptake strategies are related to leaf water status and gas exchange in plants from a ferruginous rupestrian field. American Journal of Botany, 106, 935-942.

Brodribb T. \& Hill R.S. (1997). Imbricacy and stomatal wax plugs reduce maximum leaf conductance in Southern Hemisphere conifers.Australian Journal of Botany , 45, 657-668.

Burkhardt J., Basi S., Pariyar S. \& Hunsche M. (2012). Stomatal penetration by aqueous solutions-an update involving leaf surface particles. New Phytologist, 196, 774-787. 
Burkhardt J. \& Hunsche M. (2013). "Breath figures" on leaf surfaces - formation and effects of microscopic leaf wetness.Frontiers in Plant Science, 4, 422.

Cassana F.F., Eller C.B., Oliveira R.S. \& Dillenburg L.R. (2016). Effects of soil water availability on foliar water uptake of Araucaria angustifolia . Plant and Soil , 399, 147-157.

Cavallaro A., Pereyra D.A., Goldstein G., Scholz F.G. \& Bucci S.J. (2020). Foliar water uptake in arid ecosystems: seasonal variability and ecophysiological consequences. Oecologia . doi: https://doi.org/10.1007/s00442-020-04673-1.

Cheng Y.T., Rodak D.E., Angelopoulos A. \& Gacek T. (2005). Microscopic observations of condensation of water on lotus leaves. Applied Physics Letters , 87, 194112.

Coupel-Ledru A., Tyerman S.D., Masclef D., Lebon E., Christophe A., Edwards E.J. \& Simonneau T. (2017). Abscisic acid down-regulates hydraulic conductance of grapevine leaves in isohydric genotypes only.Plant Physiology , 175, 1121-1134.

Cullen E. \& Rudall P.J. (2016). The remarkable stomata of horsetails (Equisetum ): patterning, ultrastructure and development.Annals of Botany, 118, 207-218.

Dawson T.E. \& Goldsmith G.R. (2018). The value of wet leaves. New Phytologist, 219, 1156-1169.

Earles M.J., Sperling O., Silva L.C., McElrone A.J., Brodersen C.R., North M.P. \& Zwieniecki M.A. (2016). Bark water uptake promotes localized hydraulic recovery in coastal redwood crown. Plant, Cell and Environment, 39 , 320-328.

Edwards D., Kerp H. \& Hass H. (1998). Stomata in early land plants: an anatomical and ecophysiological approach. Journal of Experimental Botany, 49, 255-278.

Eller C.B., Lima A.L. \& Oliveira R.S. (2016). Cloud forest trees with higher foliar water uptake capacity and anisohydric behavior are more vulnerable to drought and climate change. New Phytologist, 211, 489-501.

Eichert T., Goldbach H.E., \& Burkhardt J. (1998). Evidence for the uptake of large anions through stomatal pores. Botanica Acta, 111, 461-466.

Eichert T. \& Burkhardt J. (2001). Quantification of stomatal uptake of ionic solutes using a new model system. Journal of Experimental Botany , 52, 771-781.

Eichert T., Kurtz A., Steiner U. \& Goldbach H.E. (2008). Size exclusion limits and lateral heterogeneity of the stomatal foliar uptake pathway for aqueous solutes and water-suspended nanoparticles. Physiologia Plantarum , 134, 151-160.

Feild T.S., Zwieniecki M.A., Donoghue M.J. \& Holbrook N.M. (1998). Stomatal plugs of Drimys winteri (Winteraceae) protect leaves from mist but not drought. Proceedings of the National Academy of Sciences , 95, 14256-14259.

Fernandez V. \& Eichert T. (2009). Uptake of hydrophilic solutes through plant leaves: current state of knowledge and perspectives of foliar fertilization. Critical Reviews in Plant Sciences , 28, 36-68.

Fernandez V., Sancho-Knapik D., Guzman P., Peguero-Pina J.J., Gil L., Karabourniotis G., Khayet M., Fasseas C., Heredia-Guerrero J.A., Heredia A. \& Gil-Pelegrin E. (2014). Wettability, polarity, and water absorption of holm oak leaves: effect of leaf side and age. Plant Physiology , 166, 168-180.

Fuenzalida T.I., Bryant C.J., Ovington L.I., Yoon H.J., Oliveira R.S., Sack L. \& Ball M.C. (2019). Shoot surface water uptake enables leaf hydraulic recovery in Avicennia marina . New Phytologist, 224, 1504-1511.

Gouvra E. \& Grammatikopoulos G. (2003). Beneficial effects of direct foliar water uptake on shoot water potential of five chasmophytes. Canadian Journal of Botany , 81, 1278-84. 
Guzman P., Fernandez V., Khayet M., Garcia M.L., Fernandez A. \& Gil L. (2014a). Ultrastructure of plant leaf cuticles in relation to sample preparation as observed by transmission electron microscopy. The Scientific World Journal , 2014, 963921.

Guzman P., Fernandez V., Graca J., Cabral V., Kayali N., Khayet M.\& Gil L. (2014b). Chemical and structural analysis of Eucalyptus globulus and E. camaldulensis leaf cuticles: a lipidized cell wall region. Frontiers in Plant Science, 5, 481.

Guzman-Delgado P., Fernandez V., Venturas M., Rodriguez-Calcerrada J. \& Gil L. (2017). Surface properties and physiology of Ulmus laevisand U. minor samaras: implications for seed development and dispersal. Tree Physiology, 37, 815-826.

Guzman-Delgado P., Earles M.J. \& Zwieniecki M.A. (2018). Insight into the physiological role of water absorption via the leaf surface from a rehydration kinetics perspective. Plant, Cell and Environment ,41, 1886-1894.

Hayes M.A., Chapman S., Jesse A., O’Brien E., Langley J.A., Bardou R., Devaney J. Parker, J.D. \& Cavanaugh K.C. (2020). Foliar water uptake by coastal wetland plants: A novel water acquisition mechanism in arid and humid subtropical mangroves. Journal of Ecology . doi: https://doi.org/10.1111/1365-2745.13398.

Hinckley T.M., Duhme F., Hinckley A.R. \& Richter H. (1980). Water relations of drought hardy shrubs: osmotic potential and stomatal reactivity. Plant, Cell and Environment, 3, 131-140.

Hunt L., Amsbury S., Baillie A., Movahedi M., Mitchell A., Afsharinafar M., Swarup K., Denyer T., Hobbs J.K., Swarup R. \& Fleming A.J. (2017). Formation of the stomatal outer cuticular ledge requires a guard cell wall proline-rich protein. Plant Physiology , 174, 689-699.

Jones R.J. \& Mansfield T.A. (1970). Suppression of stomatal opening in leaves treated with abscisic acid. Journal of Experimental Botany, 21, 714-719.

Jordan G.J., Carpenter R.J. \& Hill R.S. (1998). The macrofossil record of Proteaceae in Tasmania: a review with new species. Australian Systematic Botany, 11, 465-501.

Kerhoulas L.P., Weisgrau A.S., Hoeft E.C. \& Kerhoulas N.J. (2020). Vertical gradients in foliar physiology of tall Picea sitchensistrees. Tree Physiology , 40, 321-332.

Laur J. \& Hacke U.G. (2014). Exploring Picea glauca aquaporins in the context of needle water uptake and xylem refilling. New Phytologist, 203, 388-400.

Li C., Wang P., van der Ent A., Cheng M., Jiang H., Lund Read T., Lombi E., Tang C., de Jonge M.D., Menzies N.W. \& Kopittke P.M. (2018). Absorption of foliar-applied Zn in sunflower (Helianthus annuus ): importance of the cuticle, stomata and trichomes. Annals of Botany, 123, 57-68.

Lawson T., James W. \& Weyers J. (1998). A surrogate measure of stomatal aperture. Journal of Experimental Botany , 49, 1397-1403.

Limm E.B., Simonin K.A., Bothman A.G. \& Dawson T.E. (2009). Foliar water uptake: a common water acquisition strategy for plants of the redwood forest. Oecologia , 161, 449-459.

Maier-Maercker U. (1983). The role of peristomatal transpiration in the mechanism of stomatal movement. Plant, Cell and Environment, 6, 369-380.

Marsal J. \& Girona J. (1997). Effects of water stress cycles on turgor maintenance processes in pear leaves (Pyrus communis ). Tree Physiology, 17, 327-333.

Martin C.E. \& von Willert A.D. (2000). Leaf epidermal hydathodes and the ecophysiological consequences of foliar water uptake in species of Crassula from the Namib Desert in southern Africa. Plant Biology , 2, 229-242. 
Merced A. \& Renzaglia K.S. (2013). Moss stomata in highly elaborated Oedipodium (Oedipodiaceae) and highly reduced Ephemerum(Pottiaceae) sporophytes are remarkably similar. American Journal of Botany, 100, 2318-2327.

Merilo E., Yarmolinsky D., Jalakas P., Parik H., Tulva I., Rasulov B., Kilk K. \& Kollist H. (2018). Stomatal VPD response: there is more to the story than ABA. Plant Physiology, 176, 851-864.

Pina A.L., Zandavalli R.B. Oliveira R.S., Martins F.R. \& Soares A.A. (2016). Dew absorption by the leaf trichomes of Combretum leprosum in the Brazilian semiarid region. Functional Plant Biology , 43, 851-861.

Resco de Dios V., Chowdhury F.I., Granda E., Yao Y. \& Tissue D.T. (2019). Assessing the potential functions of nocturnal stomatal conductance in C3 and C4 plants. New Phytologist, 223, 1696-1706.

Romero P., Botia P. \& Garcia F. (2004). Effects of regulated deficit irrigation under subsurface drip irrigation conditions on vegetative development and yield of mature almond trees. Plant and Soil , 260, 169-181.

Rundel P.W. (1982). Water uptake by organs other than roots. In Physiological plant ecology II (eds O.L. Lange, P.S. Nobel, C.B. Osmond \& H. Ziegler), pp 111-134. Springer, Berlin.

Schreiber L. \& Schonherr J. (2009). Water and solute permeability of plant cuticles. Berlin: Springer.

Schlegel T.K., Schonherr J. \& Schreiber L. (2005). Size selectivity of aqueous pores in stomatous cuticles of Vicia faba leaves.Planta, 221, 648-655.

Schreel J.D., Leroux O., Goossens W., Brodersen C., Rubinstein A. \& Steppe K. (2020). Identifying the pathways for foliar water uptake in beech (Fagus sylvatica L.): a major role for trichomes. The Plant Journal . doi: https://doi.org/10.1111/tpj.14770.

Schonherr J. \& Bukovac M.J. (1972). Penetration of stomata by liquids: dependence on surface tension, wettability, and stomatal morphology.Plant Physiology , 49, 813-819.

Schulze E.D., Lange O.L., Buschbom U., Kappen L. \& Evenari M. (1972). Stomatal responses to changes in humidity in plants growing in the desert. Planta, 108, 259-270.

Shtein I., Shelef Y., Marom Z., Zelinger E., Schwartz A., Popper Z.A., Bar-On B. \& Harpaz-Saad S. (2017). Stomatal cell wall composition: distinctive structural patterns associated with different phylogenetic groups. Annals of Botany , 119, 1021-1033.

Simonin K.A., Santiago L.S. \& Dawson T.E. (2009). Fog interception bySequoia sempervirens (D. Don) crowns decouples physiology from soil water deficit. Plant, Cell and Environment, 32, 882-892.

Spinelli G.M., Snyder R.L., Sanden B.L. \& Shackel K.A. (2016). Water stress causes stomatal closure but does not reduce canopy evapotranspiration in almond. Agricultural Water Management, 168, 11-22.

Stone E.C. (1957). Dew as an ecological factor: I. A review of the literature. Ecology, 38, 407-413.

Vesala T., Sevanto S., Gronholm T., Salmon Y., Nikinmaa E., Hari P. \& Holtta T. (2017). Effect of leaf water potential on internal humidity and $\mathrm{CO}_{2}$ dissolution: reverse transpiration and improved water use efficiency under negative pressure. Frontiers in Plant Science , 8, 54.

Turner N.C. \& Graniti A. (1969). Fusicoccin: a fungal toxin that opens stomata. Nature, 223, 1070-1071.

Zwieniecki M.A., Brodribb T.J. \& Holbrook N.M. (2007). Hydraulic design of leaves: insights from rehydration kinetics. Plant, Cell and Environment, 30, 910-921.

Table 1. Stomatal conductance and hydraulic parameters of FWU for Prunus dulcis and Pyrus communis leaves treated with fusicoccin (FC), abscisic acid (ABA), and water (control). $\mathrm{g}_{\mathrm{s}}$ : stomatal conductance of dehydrating leaves, $\mathrm{Q}_{\max }$ : maximum flux of water absorbed via the leaf surface, $\mathrm{R}_{\min }$ : minimum resistance to water absorption via the leaf surface, $t_{Q \max }$ : time at maximum flux, $\mathrm{t}_{\mathrm{Rmin}}$ : time at minimum resistance, $\mathrm{t}_{50, \Delta \mathrm{M}}$ : time when $50 \%$ of mass increment occurs, $\mathrm{t}_{50, \Psi}$ : time when $50 \%$ of water potential recovery occurs. 


\begin{tabular}{llll}
\hline & FC & ABA & Control \\
\hline $\mathrm{P}$. dulcis & & & \\
$\mathrm{g}_{\mathrm{s}}\left(\mathrm{mmol} \mathrm{m}^{-2} \mathrm{~s}^{-1}\right)$ & $313.38 \pm 3.05 \mathrm{a}$ & $-0.11 \pm 0.96 \mathrm{~b}$ & $4.73 \pm 1.63 \mathrm{~b}$ \\
$\mathrm{Q}_{\max }\left(\mathrm{mg} \mathrm{m}^{-2} \mathrm{~s}^{-1}\right)$ & $3.35 \pm 0.00 \mathrm{a}$ & $1.11 \pm 0.0 \mathrm{~b}$ & $1.19 \pm 0.00 \mathrm{~b}$ \\
$\mathrm{R}_{\min }\left(\mathrm{MPa} \mathrm{m} \mathrm{s} \mathrm{g}^{-1}\right)$ & $261.69 \pm 0.25 \mathrm{a}$ & $1037.34 \pm 0.79 \mathrm{~b}$ & $997.62 \pm 0.71 \mathrm{~b}$ \\
$\mathrm{t}_{\mathrm{Qmax}}(\min )$ & $37 \pm 0.0 \mathrm{a}$ & $100 \pm 0.1 \mathrm{~b}$ & $90 \pm 0.1 \mathrm{~b}$ \\
$\mathrm{t}_{\mathrm{Rmin}}(\min )$ & $56 \pm 0.1 \mathrm{a}$ & $133 \pm 0.2 \mathrm{~b}$ & $116 \pm 0.2 \mathrm{~b}$ \\
$\mathrm{t}_{50, \Delta \mathrm{M}}(\min )$ & $44 \pm 0.0 \mathrm{a}$ & $117 \pm 0.1 \mathrm{~b}$ & $106 \pm 0.1 \mathrm{~b}$ \\
$\mathrm{t}_{50, \Psi}(\min )$ & $44 \pm 0.0 \mathrm{a}$ & $170 \pm 0.1 \mathrm{~b}$ & $174 \pm 0.2 \mathrm{~b}$ \\
$\mathrm{P} . \operatorname{communis}$ & & & \\
$\mathrm{g}_{\mathrm{s}}\left(\operatorname{mmol~m}{ }^{-2} \mathrm{~s}^{-1}\right)$ & $350.47 \pm 10.19 \mathrm{a}$ & $74.83 \pm 4.66 \mathrm{~b}$ & $169.73 \pm 12.06 \mathrm{c}$ \\
$\mathrm{Q}_{\max }\left(\mathrm{mg} \mathrm{m} \mathrm{m}^{-2} \mathrm{~s}^{-1}\right)$ & $1.97 \pm 0.00 \mathrm{a}$ & $0.66 \pm 0.00 \mathrm{~b}$ & $1.36 \pm 0.00 \mathrm{c}$ \\
$\mathrm{R}_{\min }\left(\mathrm{MPa} \mathrm{m} \mathrm{s} \mathrm{g}^{-1}\right)$ & $583.85 \pm 0.81 \mathrm{a}$ & $1742.43 \pm 2.26 \mathrm{~b}$ & $1048.49 \pm 0.97 \mathrm{c}$ \\
$\mathrm{t}_{\mathrm{Qmax}}(\min )$ & $63 \pm 0.1 \mathrm{a}$ & $147 \pm 0.3 \mathrm{~b}$ & $82 \pm 0.1 \mathrm{a}$ \\
$\mathrm{t}_{\mathrm{Rmin}}(\min )$ & $86 \pm 0.2 \mathrm{a}$ & $208 \pm 0.5 \mathrm{~b}$ & $110 \pm 0.2 \mathrm{a}$ \\
$\mathrm{t}_{50, \Delta \mathrm{M}}(\mathrm{min})$ & $75 \pm 0.1 \mathrm{a}$ & $173 \pm 0.3 \mathrm{~b}$ & $96 \pm 0.1 \mathrm{a}$ \\
$\mathrm{t}_{50, \Psi}(\min )$ & $104 \pm 0.2 \mathrm{a}$ & $223 \pm 0.3 \mathrm{~b}$ & $139 \pm 0.2 \mathrm{a}$ \\
\hline
\end{tabular}

Data are means \pm standard errors. Values of $g_{\mathrm{s}}$ are at a $\Psi$ of $-1.75 \mathrm{MPa}$ (average $\Psi$ for all treatments and species). Within rows, values marked with different letters are significantly different according to Tukey test $(P<0.05)$ for $\mathrm{g}_{\mathrm{s}}$, and based on $95 \%$ bootstrap confidence intervals for differences between treatments in hydraulic parameters.

\section{Figure legends:}

Figure 1 . Stomatal conductance $\left(\mathrm{g}_{\mathrm{s}}\right)$ of dehydrating leaves of Prunus dulcis (a) and Pyrus communis(b) treated with fusicoccin (orange) and abscisic acid (blue), and control leaves (green) at different leaf water potentials $(\Psi)$. Thicker lines show average values for each treatment and thinner lines fit values recorded for each leaf. Black vertical lines show the average turgor loss point (solid lines) with $95 \%$ confidence intervals limits (dotted lines). Leaf replicates are $\mathrm{n}=10(\mathrm{FC}), \mathrm{n}=7$ (ABA), $\mathrm{n}=7$ (control) in $P$. dulcis and $\mathrm{n}=7$ (FC), $\mathrm{n}=6$ (ABA), $\mathrm{n}=7$ (control) in $P$. communis .

Figure 2 . Micrographs showing stomata of Prunus dulcis(a, c) and Pyrus communis (b, d) leaves treated with fusicoccin $(a, b)$ and abscisic acid (c, d). Red segments show examples of pore width measured for stomatal aperture estimations (a, c, d). When the limits of cuticular ledges were not clearly observed, stomata were excluded from the analysis (b). Note surface roughness features such as furrows (more electron-dense) and folds (more electron-lucent) influencing water condensation.

Figure 3. Cumulative change in mass ([?]M), water potential $(\psi)$ and estimated conductance $\left(\mathrm{K}_{\text {sur } \mathrm{f}}\right)$ of Prunus dulcis (a, c, e) andPyrus communis (b, d, f) leaves treated with fusicoccin (orange triangles), abscisic acid (blue squares) and water (control; green circles) over time of fog exposure. Colored regions show $95 \%$ confidence intervals for the mean predicted value (solid lines) estimated by exponential models. Models in (a) and (b) correspond to the following equation: $\Delta M=e^{A} \times\left(1-e^{\left(-B \times t^{2}\right)}\right)$ where [?] $M$ is the cumulative amount of water absorbed via the leaf surface calculated as the difference between initial leaf mass (time, $\mathrm{t}=0)$ and the mass after fog exposure $(\mathrm{t}=i)$. Models in $(\mathrm{c})$ and $(\mathrm{d})$ correspond to the following equation: $\Psi=A_{0}+e^{\left(B_{0}+B_{1} \times t^{2}\right)}$ where $\Psi$ is the leaf water potential at time $\mathrm{t}=i$. Curves in (e) and (f) were calculated following Ohm's law as $X / \psi$, where $Q$ is the instantaneous water flux into the leaf determined as the first derivative of the [?] $M$ function. The parameters fit by each model are presented in the Supporting Information. Leaf replicates are $\mathrm{n}=21(\mathrm{FC}), \mathrm{n}=22(\mathrm{ABA}), \mathrm{n}=25$ (control) in P. dulcis and $\mathrm{n}=18(\mathrm{FC}), \mathrm{n}=22$ (ABA), $\mathrm{n}=23$ (control) in P. communis .

Figure 4. Micrographs of Prunus dulcis (a, c, e) andPyrus communis (b, d, f) leaf surface. a, b: Stomatal 
complex showing guard cells (GC), subsidiary cells (SC) and the cuticle $(\mathrm{Cu})$ as the whitish layer at the most external part of the cells. Arrows indicate cuticular ledges over guard cells, and asterisks indicate the substomatal cuticle reaching and/or being part of parenchymatic cells. Red lines show the limits considered for measuring stomatal pore depth as the shortest distance between the intersection of the two lines at the inner side of the guard cells and the line at the cuticular ledges. c, d: Detail of the substomatal chamber showing the cuticle $(\mathrm{Cu})$ of subsidiary cells $(\mathrm{SC})$ and parenchymatic cells $(\mathrm{PC})$. Asterisks are in the same position as in (a) and (b). e, f: Adaxial outer wall of ordinary epidermal cells (OEC) showing the cuticle $(\mathrm{Cu})$ as the outermost cell wall $(\mathrm{CW})$ region. Epicuticular waxes $(\mathrm{EW})$ can be clearly observed inPyrus communis (f). The cytoplasm (Cy) is indicated as reference.

\section{Supporting Information:}

Table 1 . Fit results for the exponential models relating changes in mass and water potential to time used to estimate FWU parameters.

Table 2 . ANOVA results for the treatment and leaf water potential effects on stomatal conductance.

Table 3 . ANOVA results for the treatment effect on stomatal aperture.

Table 4 . ANOVA results for the treatment effect on FWU via the adaxial surface of $P$. dulcis leaves.

Table 5 . ANOVA results for the cuticle thickness variation across epidermal regions.

Figure 1. Relationships between stomatal conductance and maximum flux and stomatal aperture, and between maximum surface hydraulic conductance and stomatal conductance.
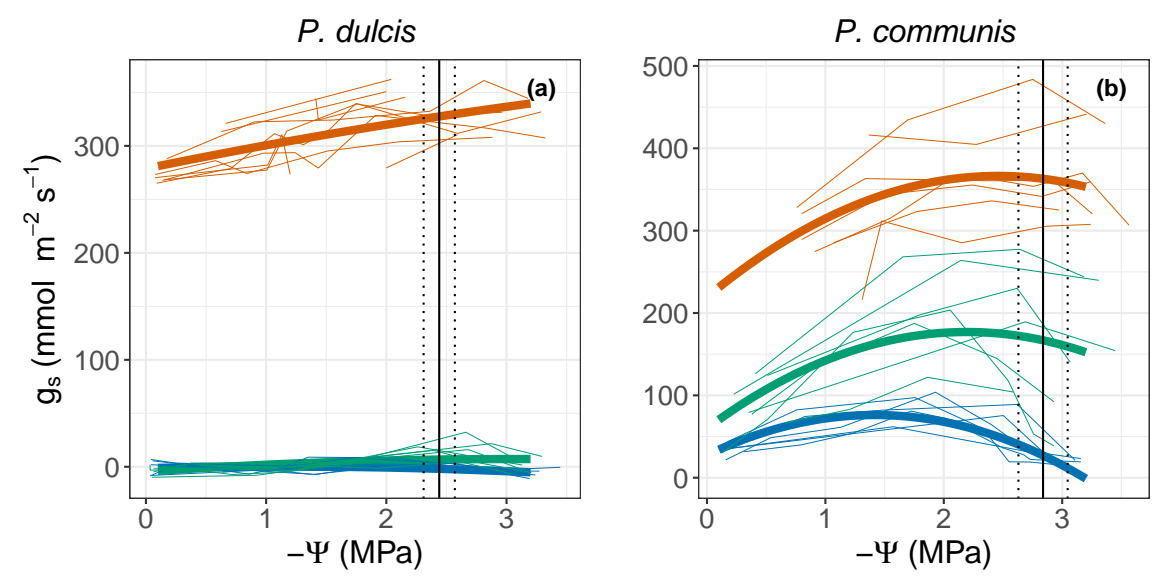


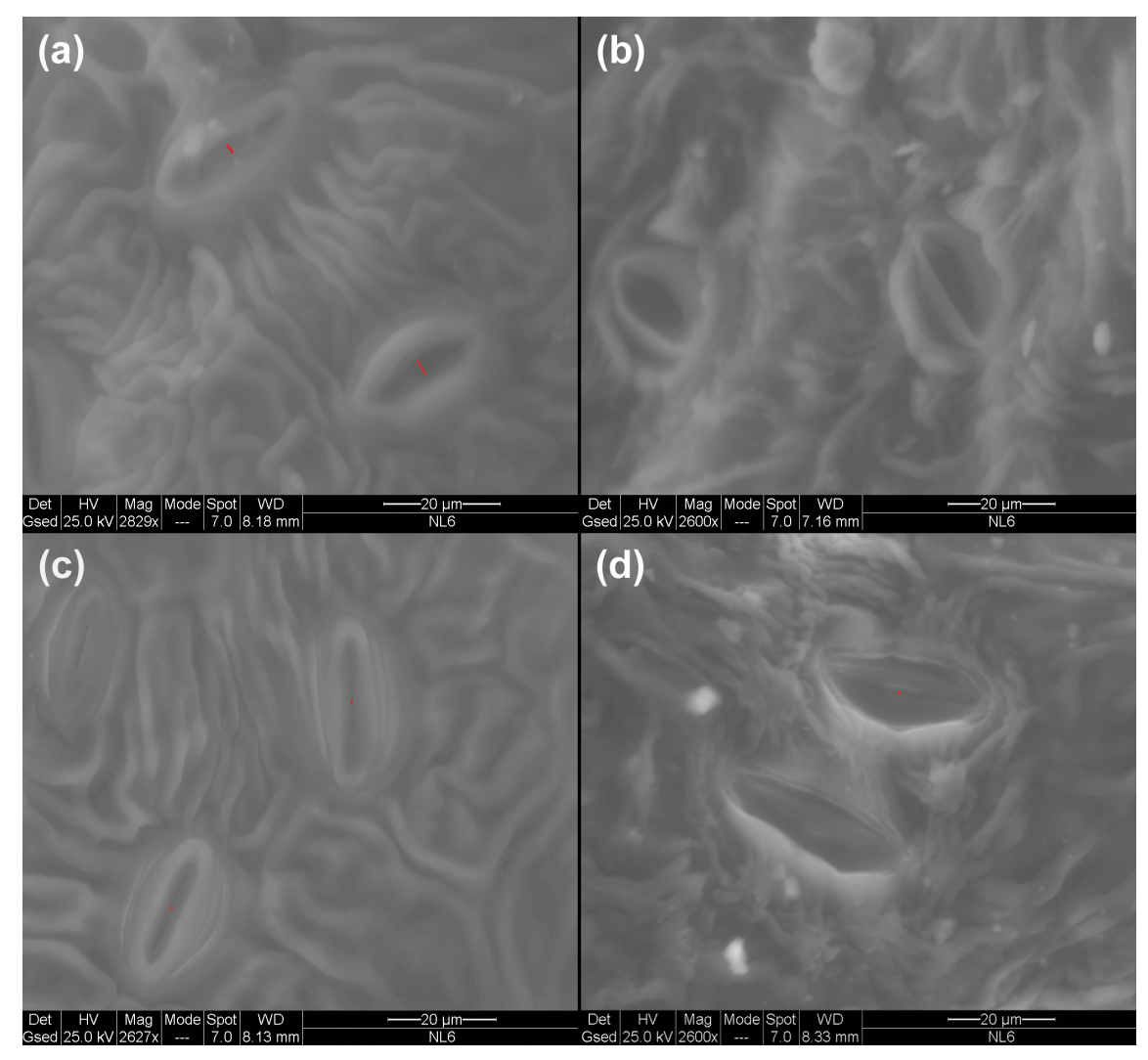



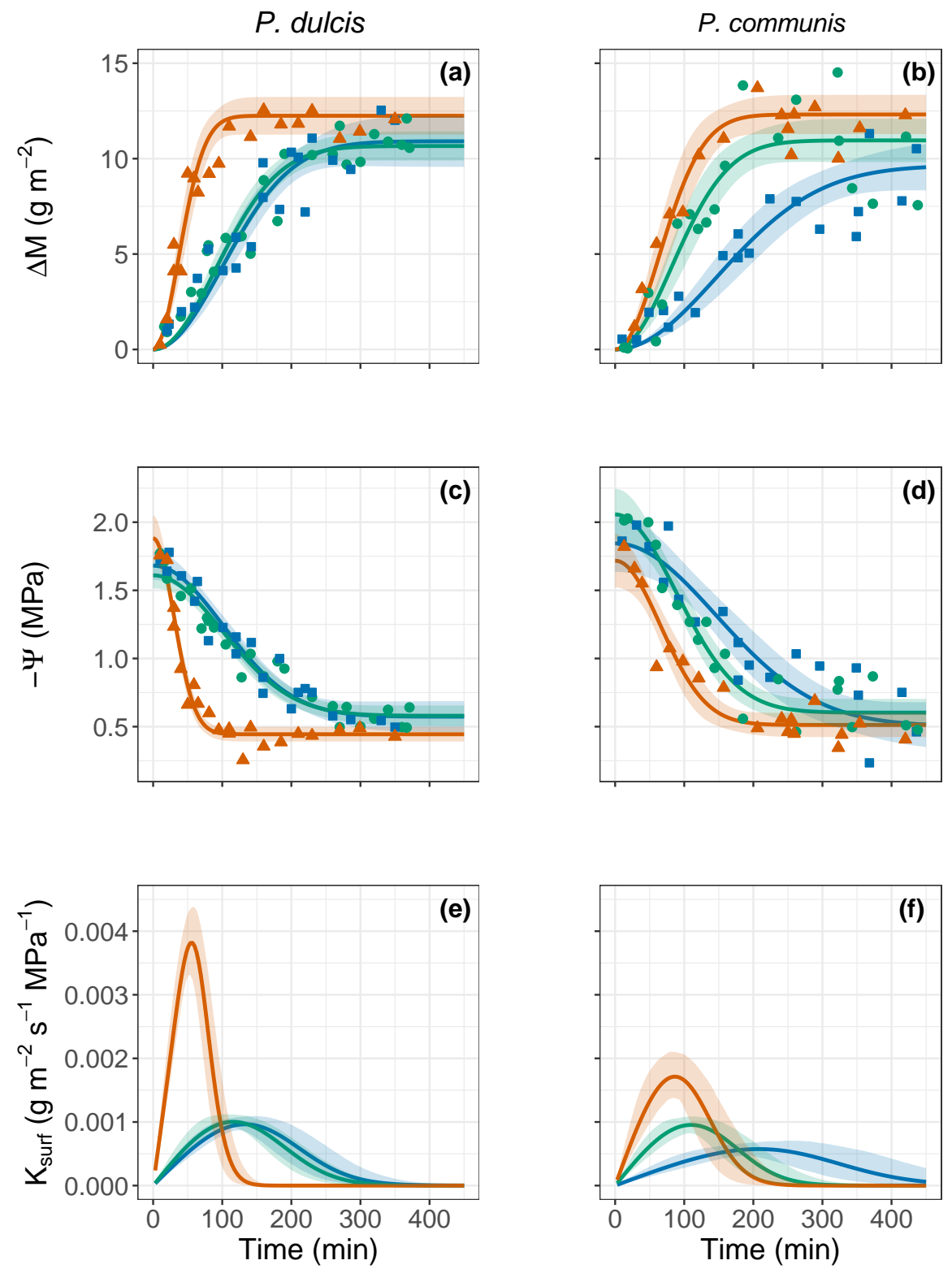


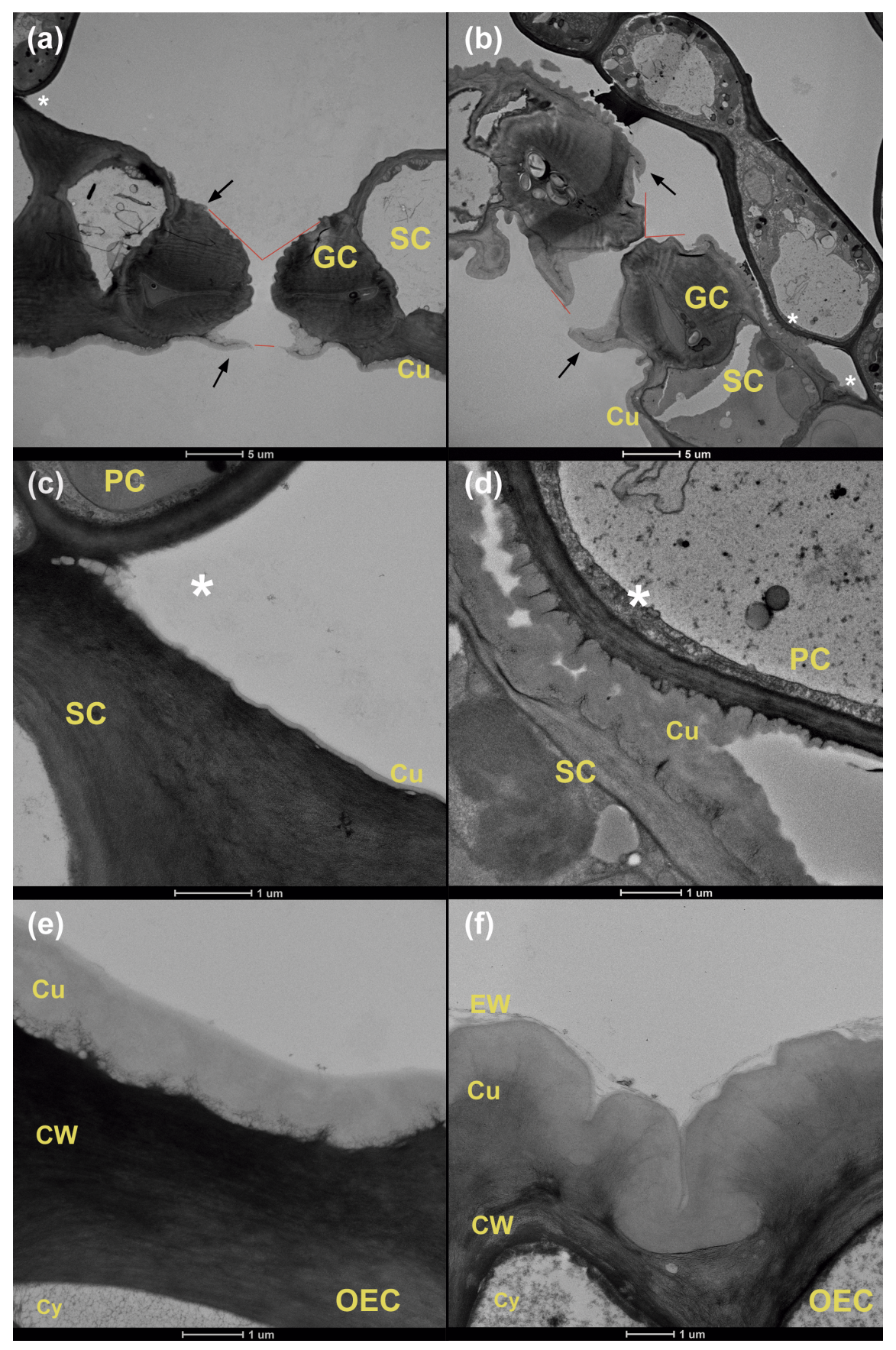

